\title{
ORGANIZATIONAL STRUCTURE ENHANCING AIRLINES EFFIECEINCY AMID THE PANDEMIC: LOW-COST CARRIERS IN THAILAND AS A CASE
}

\author{
Kannapat KANKAEW* \\ Suan Sunandha Rajabhat University, College of Hospitality Industry Management, Thailand, e-mail: kunnapat.ka@ssru.ac.th \\ Korawin KANGWOL \\ Suan Sunandha Rajabhat University, College of Hospitality Industry Management, Thailand, e-mail: korawin.ka@ ssru.ac.th
}

\section{Luidmilaa A. GUZIKOVA}

Peter the Great St. Petersburg Polytechnic University, Graduate School of Public and Financial Management, St. Petersburg, Russia, e-mail: guzikova@mail.ru

\section{Satirachai KUNGWOL}

Thai Airways International Public Co. Ltd., Thailand, e-mail: mek2546@hotmail.com

\author{
Bussaba SITIKARN
}

Mae Fah Luang University, Thailand, e-mail: bussaba@mfu.ac.th

\section{Thanasit SUKSUTDHI}

Suranaree University of Technology, School of Management Technology, Thailand, e-mail: thanasit@sut.ac.th

\begin{abstract}
Citation: Kankaew, K., Kangwol, K., Guzikova, A.L., Kungwol, S., Sitikarn, B., \& Suksutdhi, T. (2021). ORGANIZATIONAL STRUCTURE ENHANCING AIRLINES EFFIECEINCY AMID THE PANDEMIC: LOW-COST CARRIERS IN THAILAND AS A CASE. GeoJournal of Tourism and Geosites, 38(4), 1189-1194. https://doi.org/10.30892/gtg.38425-759
\end{abstract}

\begin{abstract}
The pandemic of COVID-19 has extreme impact than the intense competitors in airlines industry that never turn up in history. It derailed all airlines' operations, company's structure, strategy, and its markets which is highly impact to Thailand's tourism industry. The purpose of this study is to assess the managerial practices of low-cost carriers (LCCs) to enhance the organization's performance during COVID-19. The managerial practices concern with strategic human resources management, organizational culture, high competence personnel, and risk management affect to organizational structure. The quantitative was administered to four anonymous low-cost airlines operating in Thailand. Questionnaires were used to collect data from 150 person of each airline, hence there were 600 samples in total. The descriptive statistic and path analysis were applied. The results found that LCCs stressed greatly on the high competence personnel, followed by organizational culture, risk management, and strategic human resource management affecting organizational structure that led to efficiency and competitiveness of organization. To investigate the effect of management issues of strategic human resources management (SHRM), organizational culture (OC), high competence personnel (HQP), and risk management (RM) on low-cost carriers (LCC) in Thailand toward organizational structure (OS) which result to the competitiveness of high-performance organization (CHPO). The quantitative approach was employed by using structural equation modelling for path analysis. The data was collected by using questionnaires. There were 600 samplings from four anonymous low-cost airlines. The results found that LCCs stressed greatly on the high competence personnel, followed by organizational culture, risk management, and strategic human resource management affecting organizational structure that led to competitiveness of organization. The authors would recommend LCCs to refocus its practices to strategic human resource management during the crisis. Since, the human resource management is dealing with organization changes through the leadership and organizational culture. Finally, researchers have developed the model creating organizational structure.
\end{abstract}

Key words: strategic human resource management, low-cost airlines, organizational structure, risk management, organizational culture, the pandemic

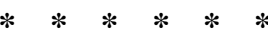

\section{INTRODUCTION}

The COVID 19, consequently, resulted the negation on all economics activities globally. It is, certainly, the tourism and transportation are affected due to the strict and prohibition to travel across the border in various countries (Scarlett, 2021). Immensely, Thailand, relies on the tourism industry as one of the major sources of its revenue. According to Bangkokbiznews (06.08.2021) reported the revenue from tourism reduced 71 percent which equal to 1.93 trillion baht comparing to 2020 . The number of international tourists decrease around 29 percent which minus 81.38 percent from the same period of 2020 . As the number of tourists diminished extensively, it is corollary to the air transportation. Currently, the fourth wave of the COVID-19 pandemic Delta variant is more severe impacting on social and economic. As a result, it caused the country GDP in 2021 grew in the range of 0.0 to 1.5 percent. Since, the number of vaccines delayed, insufficient, and inaccessible to labors. As well as, the extension of the lockdown policies from the government (Prachachat, 06.08.2021a). Furthermore, the Civil Aviation Authority of Thailand-CAAT (2021) has responded to the government policy by issuing a notice prohibiting airlines carrying passengers to and from the maximum control area and strict maximum control area from July $21^{\text {st }}, 2021$ onward. Prachachat

\footnotetext{
* Corresponding author
} 
(02.08.2021b) reported there are 29 provinces in the maximum control areas, and 37 provinces in strict control areas. Thence, there are 66 provinces in total restricted to fly while there are 77 provinces in Thailand. However, there exist some specific flight allow to fly with strict compliance to CAAT SARS safety regulations. The CAAT (2021) guidelines the regulations to operating airlines allow to carry passengers no more than 50 percent of aircraft seats, implication of social distancing onboard, temperature check, passengers and employees wearing masks all the times both at the origin and destinations. It is inevitably, the airlines are in defensive positions and absorb all burden cost occurred. The situation causes a huge impact on all airlines, especially low-cost carriers and major airlines that are in the difficulty on financial position. The airline business is vulnerable to the external changes, risks, and unpredictably phenomena. The nature of operation activities itself is complicated (Bertillo and Salando, 2013). Furthermore, low-cost carriers are highly competing purely in price. Hence, the cost reduction and wellmanaged throughout organization are vital strive to survive during the tough time. Thus, the authors interested to examine lowcost carriers in reacting and responding to the grand impact of the COVID-19. Therefore, this study aims to investigate the effect of management issues on strategic human resources management (SHRM), organizational culture (OC), high competence personnel (HQP), and risk management (RM) of low-cost carriers (LCC) in Thailand toward organizational structure (OS) which result to the efficiency and competitiveness of high-performance organization (CHPO).

\section{LITERATURE REVIEW}

The swift external environment changes have pushed organization integrate the strategic management issues with human resources. It is in term of structure fit, organizational culture, working process and external environmental fit. The organization no longer views human resources as a cost, but instead sees as valuable resources. The human resource activities need to be aligned with organization's strategy, such as recruit talents which lead to high performance organization (Kankaew and Trerattanaset, 2020a). However, the pandemic derailed the routine operation of organization. As a result, organization has to re-structure of its working processes and activities. The structure of an organization is the formal management of an organization's working system and a holistic integration of work and activities in organization (Bai et al., 2017). There are two types of organizational structures expressly; mechanical organization structure and organic structure. The mechanic structure refers to organization that is systematic management, high degree of division of work and strict control system. The employees are selected according to the specific qualifications of job requirement (Ahmady et al., 2016; Ekutu et al., 2020). In contrast, organic structure is high flexibility organization, employees are rotated, everyone can make decision in their own roles, skills, and competence, lean communication. The good organizational structure affects the performance and organizational behavior, innovation, motivation, learning and development, and sustainable human resource management (Ekutu et al., 2020).

Nonetheless, Kropp (2021) stated that working will not be as smooth as it was in the past. It will be plenty of challenges from the changing environment. Due to the impact of the COVID-19, many firms have forced employees to work from home which affects the mental health and lifestyle of its employees. It is also challenged to organization deciding pay structure in accordance with hybrid workplaces. Thus, the strategic human resources management is crucial to organization in coping with the internal and external changes. The strategic human resources management has two key dimensions, namely the development of line manager to be specialist in human resource management. It is because the line manager is interacting close to employees than human resource professional. The line manager can motivate, control, and solve the problems arise in timely manner. Other dimension is the alignment of people management strategies with environmental consistently or external fit. And the internal fit that is the integration of human resource management activities with organization's strategies (Wright and McMahan, 2011; Nisada, 2011). Thence, strategic human resource management stressed on the holistic performance of organization rather than focus on each individual. However, human resource professional should attract talents and develop the competencies of existing human resources. Thereafter, the developed-human would result to the organization competence that enhance organization different from its rivals. The competence human resource is the organization know-how values that cannot be separated. As refer to resource-based view from Barney and Clark (2009) mentioned that valuable resources are hard to imitate. Thence, the high competence personnel are a key driver of organization contend to success with the use of their intellect, logic decision-making, and expert. Unfortunately, the sudden attack of COVID-19 has shifted the complicated and challenged environment for management team and human resource professional (Hamouche, 2021).

Human resource management in airlines business, Appelbaum and Fewster (2003) stated besides customers the human resources of air carriers are considered as the firm's key competence. By reason of employees effect the company's strategy, structure, culture, and operation activities. Airlines should emphasize on strategic customer-centered, learning-oriented employee that would result to the ability to adapt of changing environment in the air transportation industry. Whereas, Ogochukwu et al. (2008) compared hr practices between domestic carriers and foreign carriers. The research suggested airline companies highlight on developing their employees with the commitment from management, continuous training employees' knowledge for success in airline business. While, Bertillo and Salando (2013) studied HRM practices in airline as a global business on recruitment, selection, and training and promotion. The airline should diversify its employees from favorite destinations for a cheaper manpower. To the extent study of Turnbull and Harvey (2020) applied resource-based view on strategic human resource management found that the rare, inimitable, non-replaceable and ability to utilize through the organization have to consistent with strategic factor market. The study of human resource management system reengineering in airline was also conducted by Roy (2013) of Aakash Airways for improving productivity, service quality, and sustainable capacity. In addition, the strategic human resource management was recommended to implement for improving the flight safety in airlines company (Patton, 2015). Where, in Thailand, Kampitak and Yoopetch (2018) investigated the human resource practices in airline company on the turnover intention. They found job satisfaction has an effect to employees' retention rather than organizational culture, retention strategies, and compensation and benefits. It is worth noticing the gap to study how strategic human resource management and high-competence personnel effect airline's organization structure, especially during the pandemic crisis. Hence, the hypotheses were pinpoint on: 
H1: Low-cost airlines focus on strategic human resource management during the pandemic handling which effect to organizational structure

H2: Low-cost airlines focus on high-competence personnel during the pandemic handling which effect to organizational structure

COVID-19 was considered as a crisis to society and business. The definition of crisis was segregated into two camps as Coombs (2015) stated the first camp is the disaster that is the sudden event derailed routines of the system and require guidelines of to handle. The other is organization crisis that is threaten and unpredictable event related to safety, economic, health, and environmental. Consequently, organization has to quickly change and adapt to mitigate unfavorable effects. According to Dawson (2003) changes were categorized into technical, governance, and culture. Notwithstanding, Bhitakburi (2020) mentioned four types of change namely; structural, cost cutting, process, and cultural that depending on the management's perspective to cope with the occurrence of the changes. Literally, it is the changes of hierarchy in negotiations, coordination, and authority of relationships in organization. It is also enhancing the moral system in organization on building positive culture. However, as mentioned previously the sudden change is a kind of crisis. Therefore, organization should implement the risk management. The ERM Thailand (2021) defined risk management as a process by which people throughout organization are involved in identifying, analyzing, and anticipating potential risks. Then, they jointly figure out to manage risks at an appropriate level so that the organization can achieve its objectives.

Ketsarin (2021) claimed that globalization is challenging for both private and public organization. Thereby, organizations require control system and internal audit with good governance and risk management. The COSO model is widely used as a risk management model. It composes of five processes including; control environment, risk assessment, control activities, information and communication, and monitoring. The COSO risk management is a process design for corporate executives and employees responsible to lead organization success its objectives. The model has a reliable financial reporting system, and compliance with rules and regulations. Meanwhile, ERM Thailand (2021) added that enterprise risk management (ERM) is the overall controlling of factors and activities in organization. Its efforts to reduce the opportunity and causes of the risk, assessed, monitored and controlled. There are eight steps consisting of analyze internal environment, set up objectives, identify the event, risk assessment, risk response, control activities, communication and information, and monitoring. Forasmuch as, in airline business mainly highlighted on safety risk rather than the risk that effect to organization. There are myriad studies on risk in airline business, such as Li et al. (2020) revealed the technologies correlate with airline flight operations; Elkhweldi and Elmabrouk (2015) examined risk management process on airlines operation (Qiu et al., 2020) specifically during aircraft flight operations, and human performance on ground operations; Bourgeois-Bougrine (2020) investigated fatigue risk management systems toward airline's crew members; Dudek et al. (2020) represented the process of risk management in aviation precisely the identification of hazard and risk assessment in air traffic management. As it can be seen that the majority of risk study in airlines mainly focusing on safety, flight operation, and hazard identification. Since, the most priority concern in aviation is the safety. And the safety issue was embedded throughout organization structure by cultivating as the safety culture of the airlines. Undoubtedly, the sudden and unexpected risk could become crisis to organization, such as the pandemic. Yet, there is no many studies on the risk toward airlines' organization rather than safety and hazard risk. For this reason, the hypothesis three was set;

\section{H3: Low-cost airlines focus on risk management during the pandemic handling which effect organizational structure}

Kankaew and Trerattanaset (2020b) cited that organizational culture is the expectations, beliefs, shared valued that engage people and the system. It encourages the sense of identity, commitment, and communication. In sum, the organizational culture is the motivation and social energy within organization that inspire people motive to reach the company goals. Thought, the propre culture has to be identified and socialized for the firm's employees to believe and change behavior. This would enhance firm in building strength performance and acquire competitive advantages (Pathiranage et al., 2020). The organizational culture assessment instrument (OCAI) categorized organizational culture according to the importance of organization in terms of security, flexibility on internal and external environments, and people and customer oriented (Ližbetinová et al., 2016). These elements namely 'clan' is high flexible organization, internal focus rather than external; 'adhocracy' is high flexible but emphasize on external than internal environment; 'hierarchy' is stressed on controlling, strict to the rules and regulations (Ližbetinová et al., 2016), and internal issues; and last type 'market' is the culture that highlight on controlling and external environment.

Thai culture system in a workplace, peculiarly in public organization is hierarchical, high-power distance, patronage, face-saving, personal connection, and bureaucratic (Kankaew and Trerattanaset, 2020b). Despite the fact, low-cost airlines are privately own that require lean management. It is a system which support employees in making decision to solve the problem for passenger in timely manner. Jitklongsub and Suveatwatanakul (2020) recommended airlines cultivating three factors to encourage flight attendants' performance including; organizational culture, business ethics, and employee engagement. Whereon, organizational culture was determined by three keys components including; individual and interpersonal characteristics, and task level. The individual and interpersonal characteristic are for example; psychological traits, aptitudes, competencies, method of work, and attitude and behavior. Meanwhile, the task level refers to a work that can be done by employees at any level for reaching firm's strategy. The other task level is a sub-work which required different team of employee to accomplished. At this pandemic time, Spicer (2020) advised organization to realign its culture tally to the macro environment changes. The organization should examine its culture values, such as existing culture and the environment, transformation process, collective engagement, diverse state of people psychology.

H4: Low-cost airlines focus on organizational culture during the pandemic handling which effect organizational structure 


\section{MATERIALS AND METHODS}

The quantitative approach was employed on which the data collected by administering questionnaires. The sample group were employees from four anonymous low-cost carriers operating in Thailand. The researchers applied the abbreviation to represent the air carriers as AA, NA, TA, and VA. The systematic sampling was used in selecting the respondents. There were 150 persons from each sample airline, hence there were 600 respondents in total. Researchers employed both descriptive statistic and inferential statistic by using structural equation modelling (SEM). The fit indices were tested for SEM as followed; CMIN/DF $=.929, \mathrm{CFI}=1.000, \mathrm{GFI}=.999, \mathrm{RFI}=.995, \mathrm{NFI} 1.000, \mathrm{RMSEA}=.032$.

\section{RESULTS AND DISCUSSION}

The respondents were male 302 persons and female 293 persons. The majority of respondents worked in the airlines 5-10 years 195 persons, followed by 10-15 years 155 persons, and 1-5 years 150 persons. They hold the position as senior operation officers 243 persons, operation officers 192 persons, and supervisor 91 persons. The data was concluded in Figure 1.

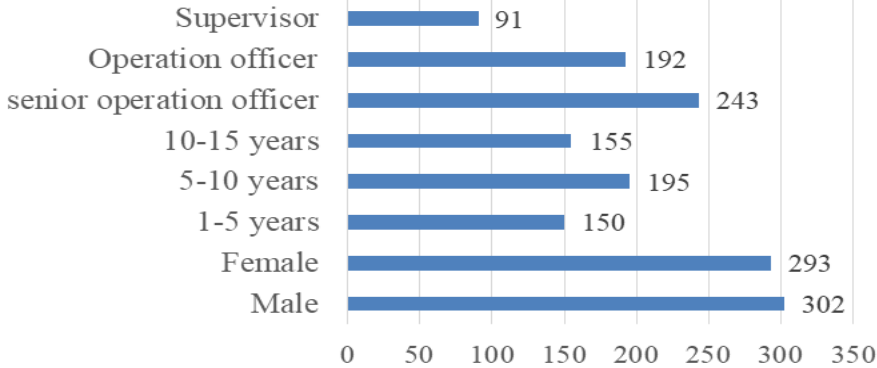

Figure 1. Respondent Demographic

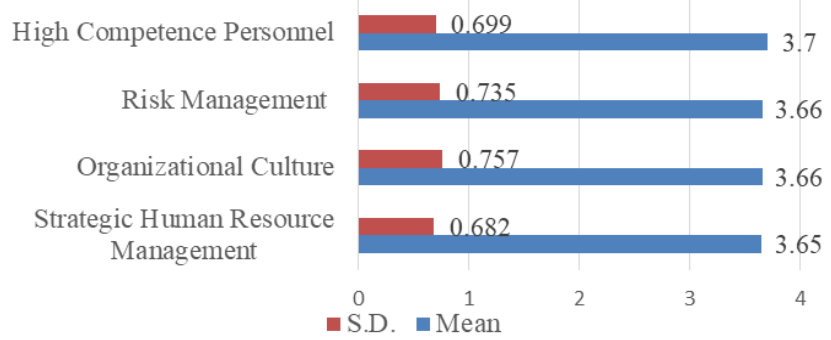

Figure 2. Mean and SD. Values of Factors Affecting Low-Cost Carriers'Organizational Structure

The descriptive statistic in Figure 2 revealed that low-cost carriers (LCCs) highest emphasized on high competence personnel with mean value 3.70 that affected to organizational structure. It is followed by organizational culture, risk management with the equal mean values 3.66. Whilst, the strategic human resource management (SHRM) ranked least important with mean values equal to 3.65. Meanwhile, the standard deviation of all variables is in between 0.6-0.7. These could be interpreted that during the pandemic LCCs in Thailand mainly accentuated on the competence personnel. That is the capability of personnel could strengthen organizational structure than other elements. Nevertheless, the mean values of each factor are not different significantly. Thus, it means that LCCs are still aware the importance of other factors namely organizational culture, risk management and SHRM. In this study, the high competence personnel refer to employees who are keen to learn and developing themselves continuously. In addition, these people are concentrated on teamwork, having a good knowledge of the company products and process, employee able to perform the job without close control, and employee committed to the performance result. While, organizational culture is the workplace where employees engage to the team, department, and organization. Leaders support and motivate subordinates. The creativity has been set in organization's atmosphere. And the clear rules and regulations in the workplace have been implemented. In consideration of risk management, the organization should assess and follow up the risk that might occur throughout organization. The discrepancy plan was set up for both internal and external crisis. Moreover, the communication of the risk management plan must be disclosed to all employees, and the capability of organization in controlling the risk at tolerant level. For SHRM in this study was highlighted on the role of line manager in each department, the application of pay performance system, and 360-degree appraisal system. It is included the development plan of employees has to be in line with the company strategies. Therefore, the path analysis was tested to assess the influence of each factor towards organizational structure. That would lead to the competence for high-performance organization. The regression analysis of all variables was examined as demonstrate in Table 1.

Table 1. Regression analysis of Variables

\begin{tabular}{|c|c|c|c|c|c|c|}
\hline & & & Estimate & S.E. & C.R. & $\mathrm{p}$ \\
\hline OS & $<---$ & SHRM & -.076 & .031 & -2.401 & .016 \\
\hline OS & $<---$ & OC & .315 & .028 & 11.091 & $* * *$ \\
\hline OS & $<---$ & HQP & .350 & .031 & 11.397 & $* * *$ \\
\hline OS & $<---$ & RM & .255 & .029 & 8.728 & $* * *$ \\
\hline CHPO & $<---$ & OS & .318 & .036 & 8.902 & $* * *$ \\
\hline CHPO & $<---$ & SHRM & .202 & .028 & 7.294 & $* * *$ \\
\hline CHPO & $<---$ & RM & .230 & .027 & 8.483 & $* * *$ \\
\hline CHPO & $<---$ & OC & -.015 & .027 & -.567 & .571 \\
\hline CHPO & $<---$ & HQP & .172 & .030 & 5.796 & $* * *$ \\
\hline
\end{tabular}

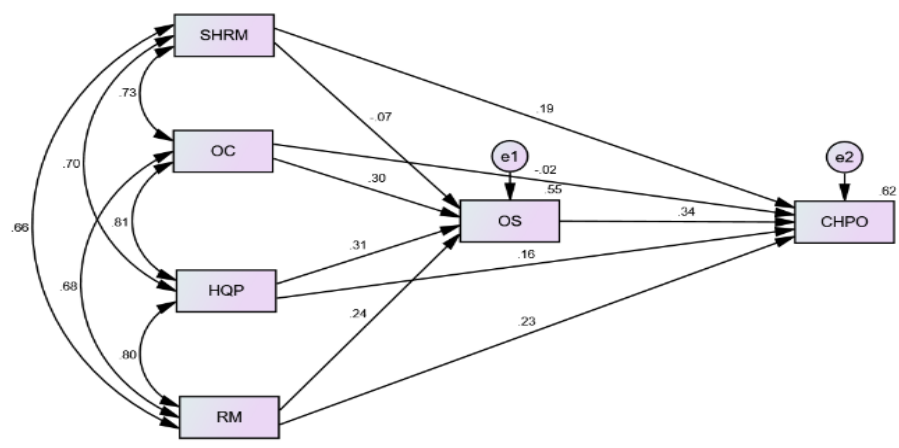

Figure 3. Path Analysis Model

As refer to Table 1, the organizational culture has no effect to the organization competencies for high-performance where the regression coefficient is higher than 0.05 and C.R. value -0.567 . Then, the data from Table 1 was created into structural equation modelling and path analysis was appraised as illustrate in figure 3 below. The path analysis of exhibited the high competence personnel has greater effect to the organizational structure than other factors with standard regression weight 0.31 . The second factor is organizational culture with its standard regression weight 0.30 . While, the third and fourth factors are risk 
management and strategic human resource management with standard regression weight 0.24 and 0.07 respectively. Consequently, the square multiple correlation $\left(R^{2}\right)$ of the organizational structure is 0.55 . This means that the variation of organizational structure was derived from all factors 55 percent. In the meantime, the organizational structure has highest effect to the competitiveness of high-performance organization followed by risk management, strategic human resource management, high competence personnel, and organizational culture. The standard regression weights are $0.34,0.23,0.19$, 0.16 , and - 0.02 correspondingly. The competitiveness of high-performance organization $(\mathrm{CHPO}) R^{2}$ is 0.62 that explained all factors affect the variation of CHPO 62 percent. The direct effect (DE), indirect effect (IE), and total effect (TE) were calculated as demonstrated in Table 2. According to Table 2, the organizational structure was affected by high quality personnel with effect size 0.313 , pop up by organizational culture, risk management, and strategic human resource management. The effect size of each factor is $0.303,0.240$, and -0.066 . At the same time, the all mentioned factors have indirect

Table 2. Direct, Indirect, and Total effect of factors to competitiveness of high-performance organization

\begin{tabular}{|c|c|c|c|c|c|c|c|c|c|c|}
\hline Effect & \multicolumn{2}{|c|}{ RM } & \multicolumn{2}{c|}{ HQP } & \multicolumn{2}{c|}{ OC } & \multicolumn{2}{c|}{ SHRM } & \multicolumn{2}{c|}{ OS } \\
\hline & OS & CHPO & OS & CHPO & OS & CHPO & OS & CHPO & OS & CHPO \\
\hline DE & .240 & .232 & .313 & .165 & .303 & -.016 & -.066 & .189 & .000 & .340 \\
\hline IE & .000 & .081 & .000 & .111 & .000 & .100 & .000 & -.024 & .000 & .000 \\
\hline TE & .240 & .313 & .313 & .276 & .303 & .084 & -.066 & .165 & .000 & .340 \\
\hline
\end{tabular}

effect to the competitiveness of high-performance organization collated viz high-quality personnel, organizational culture, risk management, and strategic human resource management. Thereby, the effect sizes are $0.111,0.100,0.081$, and -0.024 . It is worth noticing that the organizational structure act as mediator role that has effect size to the competitiveness of high-performance organization.

\section{CONCLUSION AND DISCUSSION}

Be pointed out here that there is slightly different of LCCs' employees' perspective during the pandemic on four factors affecting organizational structure. The descriptive statistic, it can be concluded the hypotheses $\mathrm{H} 1$ to $\mathrm{H} 4$ that LCCs prioritize high quality or competence personnel during the tough situation. Whilst, the second factor underlines on organizational culture. Then, the last two factors are risk management and strategic human resource management. Insofar as, the path analysis represented the same result. LCCs pay attention greater on high competence personnel, followed by organizational culture, risk management during the COVID-19. Contrarily, the strategic human resource management has placed in least important factor to implement during the pandemic. It is worth noticing that the respondents believed high-quality personnel would affect to organizational structure. That is resulting to the competitiveness of the airlines during the pandemic. In addition, the organization needs to acquire new talents to keep up with the growth. As Johnson and Suskewicz (2020) suggest leader to build teams and talent prior implementing the organization's strategy. It is consistent to Nisada (2011) states that high competence personnel could be developed as organization's capital. This capital is the know-how of organization which embedded in each individual and cannot be segregated. In associated with resource-based view theory of (Barney and Clark, 2009) explained highly qualified human capital is a scarce and inimitable resource. The human capital drives organization with their expertise, intellectual, and rational decision-making. The high competence personnel support the corporate capital including; organizational structure, system planning and controlling, coordination and communication effectively. Especially, in the crisis that organizations are confronting of information technology and society changes.

In the service industry, specifically, the airlines where the products and services are quite similar. Hence, human resources are the keystone creating customer experiences that distinct from rivals (Branson, 2013). Consequently, air carriers should continuously put the accent on knowledge, skills, and attitude developing of its employees to be ready amid the changes. It is clearly can be viewed the importance of human resources to organizations. However, the results of this study uncover that LCCs have least accent among other factors. Despite the fact that, strategic human resource management is considered as a key issue in developing personnel competency for achieving organizational goals.

The human resource professionals must understand the internal and external business context. It is for the purpose of creating organizational competence that align with business strategy for competitiveness and coping with the fluctuated environment. As refer to Ulrich et al (2012) proposed the competencies for human resource professionals should be strategic positioner, capability builder, change champion, human resource innovator and integrator, technology proponents, and credible activist. For this reason, the authors would recommend LCCs to refocus its practices to strategic human resource management during the crisis. This is identical to Imam (2020) pointed up the significance of human resource management roles for airlines during crisis. Since, the human resource management is dealing with organization changes through the leadership and organizational culture. The researchers suggest airlines to accentuate on strategic human resources management. Since, it helps organization to metamorphose to the changes internally and externally. Finally, researchers have developed the model creating organizational structure as shown in below Figure 4.

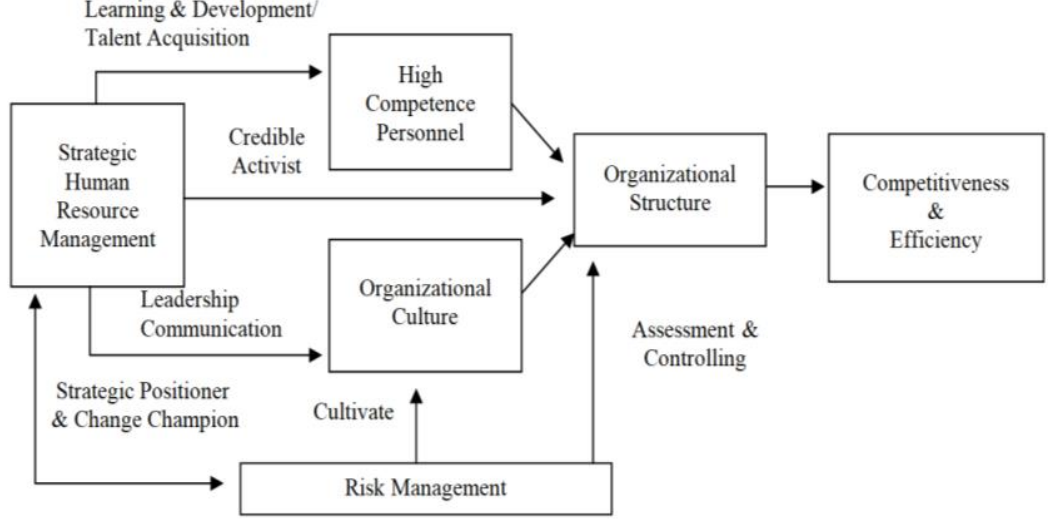

Figure 4. Organizational Structure Building Model 


\section{REFERENCES}

Ahmady, A.G., Mehrpour, M., \& Nikooravesh, A. (2016). Organizational Structure. Social and Behavioral Sciences, $230,455-462$. https://doi.org/10.1016/j.sbspro.2016.09.057

Appelbaum, H.S., \& Fewster, M.B. (2003). Global Aviation Human Resource Management: Contemporary Compensation and Benefits Practices. Management Research News, 26(7), 59-71. https://doi.org/10.1108/01409170310783592

Bai, W., Feng, Y., Yue, Y., \& Feng, L. (2017). Organizational Structure, Cross-Functional Integration and Performance of New Product Development Team. Procedia Engineering, 174, 621-629. https://doi.org/ 10.1016/j.proeng.2017.01.198

Bangkokbiznews. (2021). The Ministry of Tourism and Sports reveals the revenue from tourism industry of the first 11 months in 2020 decreased swiftly 1.93 trillion. Retrieved from www. Bangkokbiznews.com.

Barney, B.J., \& Clark, N.D. (2009). Resource-based theory: Creating and sustaining competitive advantage. Oxford Press, (pp. 57-72) Oxford, The United Kingdom

Bertillo, J.B., \& Salando, J.B. (2013). Human Resource Management Practices in an Airline Industry: The British Airways Global Perspective, 1-14. https://doi.org.10.2139/ssrn.2292797

Bhitakburi, K. (2020). Enhancing the Middle Management at Individual Level for Organizational Change of an International Airline in Asia. ABAC ODI Journal Vision, Action, Outcome, 7(1), 184-208.

Bourgeois-Bougrine, S. (2020). The illusion of Aircrews' Fatigue Risk Control. Transportation Research Interdisciplinary Perspectives, 4(2020), 100104. https://doi.org/10.1016/j.trip.2020.100104

Branson, R. (2013). Like a Virgin, CPI Group, London, United Kingdom.

Civil Aviation Authority of Thailand-CAAT. (2021). CAAT News 28/2564. Retrieved from www. caat.or.th

Coombs, T.W. (2015). Ongoing Crisis Communication: Planning, Managing, and Responding (4th ed.), SAGE, Singapore.

Dawson, P. (2003). Understanding Organizational Change: The Contemporary Experience of People at Work, SAGE, London, The United Kingdom.

Dudek, E., Krzykowska-Piotrowska, K., \& Siergiejczyk, M. (2020). Risk Management in (Air) Transport with Exemplary Risk Analysis Based on the Tolerability Matrix. Transport Problems, 15(2), 143-156. https://doi.org/10.21307/tp-2020-027

Ekutu, A. C., Edeh, O. F., Alamina, P. U., Fern, S. Y., Kumari, P., \& Eder, E. J. (2020). Effects of Organizational Structure on Employee Resilience. Journal of Business School, 3(2), 75-85. https://doi.org/10.26677/TR1010.2020.616

Elkhweldi, A.M., \& Elmabrouk, K.S. (2015). Aviation Risk Management Strategies. Proceeding of the 2105 International Conference on Industrial Engineering and Operations Management, Dubai, United Arab Emirates, March 3-5, 2015.

Hamouche, S. (2021). Human Resource Management and the COVID-19 Crisis: Implications, Challenges, Opportunities, and Future Organizational Directions. Journal of Management \& Organization, 1-16. https://doi.org/10.1017/jmo.2021.15

Imam, H. (2020). New Normal Perspective of Post COVID-19 in the Airline Industry. Preprints 2020, 2020120723. https://doi.org/10.20944/preprints202012.0723

Jitklongsub, J., \& Suveatwatanakul, C. (2020). Determinants of Business Ethics, Organizational Culture, Employee Engagement, and Job Performance of Flight Attendant. Dusit Thani College Journal, 14(1), 466-486.

Johnson, W.M., \& Suskewicz, J. (2020). Lead from the Future, Harvard Business Review Press, Boston, USA.

Kampitak, T., \& Yoopetch, C. (2018). The Study of Employee Retention in Thailand's Airlines Industry. Dusit Thani College Journal, 12(2), 193-208.

Kankaew, K., \& Trerattanaset, P. (2020a). Wiwatthanākān Kānčhatkān Sapphayākọ̄n Manut Chœ̄ngkon Yut [The Evolution of Strategic Human Resource Management]. Journal of Management Science Chaing Rai Rajabhat University, 15(2), $92-116$ (in Thai).

Kankaew, K., \& Treruttanaset, P. (2020b). The Organizational Culture Affecting Job Performance of Newly Hired Employees: A Case Study of the Customs Bureau at Bangkok Suvarnabhumi International Airport, Thailand. In Corporate Leadership and Its Role in Shaping Organizational Culture and Performance (pp. 129-155). IGI Global Publishing, Hershey, USA.

Ketsarin, P. (2021). Risk Management and Internal Audit. Government Audit and Development Office, Comptroller General's Department. Retrieved from: www.med.mahidol.ac.th.

Kropp, B. (2021). 9 Trends that will shape work in 2021 and beyond. Harvard Business Review. Retrieved from www.hbr.org.

Li, J., Wu, J., Wang, G., Wang, W., Wu, M., \& Xu, J. (2020). Architecture and Key Technologies for Airline Operational Control System Based on Risk Preprocessing. 2020 IEEE 4th Information Technology, Networking, Electronicand Automation Control Conference (IYNEC), 215-223. https://doi.org/10.1109/ITNEC48623.2020.9085064

Ližbetinová, L., Lorincová, S., \& Caha, Z. (2016). The Application of the Organizational Culture Assessment Instrument (OCAI) to Logistics Enterprises. International Journal of Maritime Science \& Technology, 63(3), 170-176.

Nisada, W. (2011). Kānčhatkān Sapphayākō̄n Manut Chōengkon Yut [Strategic Human Resource Management], Golden Time Printing, Thailand.

Ogochukwu, U., Chinonye, U., \& Callistus, I. (2008). Benchmarking Human Capital Strategies of Domestic and Foreign Airlines: Evidence from Nigeria. International Journal of Development and Management Review, 3(1), 36-55.

Patton, J. (2015). Human Resource Management (HRM) in the Aviation Industry. The Journal of Global Business Management, 11(1), 1-12.

Pathiranage, Y.L., Jayatilake, V.K.L., \& Abeysekera, R. (2020). A Literature Review on Organizational Culture towards Corporate Performance. International Journal of Management, Accounting and Economics, 7(9), 522-544.

Prachachat. (2021a). Purchasing power across the country has collapsed, unemployment increases, stores gradually close, and asks for credit extensions. Retrieved from www. Prachachat.com.

Prachachat. (2021b). The Government Gazette announced the expansion of the dark-red area to 29 provinces starting from August $3 r d$. Retrieved from www. Prachachat.com.

Qiu, S., Yao, D., Wang, Z., \& Zhao, G. (2020). Research on Airline Operational Risk Management and Control Method. IOP Conf. Series. Materials Science and Engineering, 715(2020) 012053. https://doi.org/10.1088/1757-899X/715/1/012053

Roy, S. (2013). Flying Low: HR Challenges in the Airline Industry. IPBJ, 5(1), 49-75.

Scarlett, G.H. (2021). Tourism recovery and the economic impact: A panel assessment. Research in Globalization, $3,100044$.

Spicer, A. (2020). Organizational Culture and COVID-19. Journal Of Management Studies, 57(8), 1737-1740. https://doi.org/10.1111/joms.12625

Turnbull, P.J., \& Harvey, G. (2020). Ricardo Flies Ryanair: Strategic Human Resource Management and Competitive Advantage in a Single European Aviation Market (SEAM). Human Resource Management Journal. https://doi.org/10.1111/1748- 8583.12315

Ulrich, D., Younger, J., Brockbank, W., \& Ulrich, M. (2012). HR from the Outside In, McGrawHill, Singapore.

Wright, P. M., \& McMahan, G. C. (2011). Exploring Human Capital: Putting 'Human' Back into Strategic Human Resource Management. Human Resource Management Journal, 21(2), 93-104. https://doi.org/10.1111/j.1748-8583.2010.00165.x

*** ERM Thailand. (2021). Risk Management and COSO model. http://ermthailand.blogspot.com/p/erm-coso.html. 